\title{
Front Matter: Volume 6782
}

, "Front Matter: Volume 6782," Proc. SPIE 6782, Optoelectronic Materials and Devices II, 678201 (19 November 2007); doi: 10.1117/12.784844

SPIE. Event: Asia-Pacific Optical Communications, 2007, Wuhan, China 


\section{PROCEEDINGS OF SPIE}

\section{Optoelectronic Materials and Devices II}

\section{Yoshiaki Nakano \\ Editor}

2-5 November 2007

Wuhan, China

Sponsored by

SPIE

COS-Chinese Optical Society (China)

CIC-China Institute of Communications (China)

The People's Government of Wuhan Municipality (China)

Cooperating Organizations

WNLO-Wuhan National Laboratory for Optoelectronics (China)

The Productivity Promotion Center of Wuhan East Lake Hi-Tech Development Zone (China)

Wuhan Research Institute of Posts and Telecommunications (China)

The State Optoelectronics and Information Industry Base of China (China)

Published by

SPIE

Part One of Two Parts

Volume 6782 
The papers included in this volume were part of the technical conference cited on the cover and title page. Papers were selected and subject to review by the editors and conference program committee. Some conference presentations may not be available for publication. The papers published in these proceedings reflect the work and thoughts of the authors and are published herein as submitted. The publisher is not responsible for the validity of the information or for any outcomes resulting from reliance thereon.

Please use the following format to cite material from this book:

Author(s), "Title of Paper," in Optoelectronic Materials and Devices II, edited by Yoshiaki Nakano, Proceedings of SPIE Vol. 6782 (SPIE, Bellingham, WA, 2007) Article CID Number.

ISSN 0277-786X

ISBN 9780819469458

Published by

SPIE

P.O. Box 10, Bellingham, Washington 98227-0010 USA

Telephone +1 3606763290 (Pacific Time) · Fax +1 3606471445

SPIE.org

Copyright (C 2007, Society of Photo-Optical Instrumentation Engineers

Copying of material in this book for internal or personal use, or for the internal or personal use of specific clients, beyond the fair use provisions granted by the U.S. Copyright Law is authorized by SPIE subject to payment of copying fees. The Transactional Reporting Service base fee for this volume is $\$ 18.00$ per article (or portion thereof), which should be paid directly to the Copyright Clearance Center (CCC), 222 Rosewood Drive, Danvers, MA 01923. Payment may also be made electronically through CCC Online at copyright.com. Other copying for republication, resale, advertising or promotion, or any form of systematic or multiple reproduction of any material in this book is prohibited except with permission in writing from the publisher. The CCC fee code is $0277-786 \mathrm{X} / 07 / \$ 18.00$.

Printed in the United States of America.

Publication of record for individual papers is online in the SPIE Digital Library.

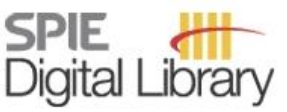

SPIEDigitallibrary.org

Paper Numbering: Proceedings of SPIE follow an e-First publication model, with papers published first online and then in print and on CD-ROM. Papers are published as they are submitted and meet publication criteria. A unique, consistent, permanent citation identifier (CID) number is assigned to each article at the time of the first publication. Utilization of CIDs allows articles to be fully citable as soon they are published online, and connects the same identifier to all online, print, and electronic versions of the publication. SPIE uses a six-digit CID article numbering system in which:

- The first four digits correspond to the SPIE volume number.

- The last two digits indicate publication order within the volume using a Base 36 numbering system employing both numerals and letters. These two-number sets start with 00, 01, 02, 03, 04, 05, $06,07,08,09,0 A, 0 B \ldots 0 Z$, followed by $10-12,20-2 Z$, etc.

The CID number appears on each page of the manuscript. The complete citation is used on the first page, and an abbreviated version on subsequent pages. Numbers in the index correspond to the last two digits of the six-digit CID number. 


\section{Contents}

\section{Part One}

xv Conference Committee

\section{SILICON PHOTONICS SYMPOSIUM}

678202 Si photonics: past, present, and future (Invited Paper) [6782-01]

K. Wada, The Univ. of Tokyo (Japan)

678203 Micro/nanoscale silicon based photonic devices (Invited Paper) [6782-02]

Z. Zhou, Wuhan National Lab. for Optoelectonics (China) and Georgia Institute of Technology (USA)

678204 Ge nanostructures doped silica-on-silicon waveguides (Invited Paper) [6782-03]

H. Ou, T. P. Rørdam, K. Rottwitt, F. Grumsen, A. Horsewell, R. W. Berg, P. Shi, L. C. Gontard,

R. E. Dunin-Borkowski, Technical Univ. of Denmark (Denmark)

\section{ALL-OPTICAL PROCESSING}

678205 Photonic buffer memory based on polarization bistability in VCSELs (Invited Paper) [6782-04]

H. Kawaguchi, Nara Institute of Science and Technology (Japan) and CREST, Japan Science and Technology Agency (Japan)

$67820840 \mathrm{~Gb} / \mathrm{s}$ all-optical digital encoder/comparator based on semiconductor optical amplifiers [6782-07]

Y. Wang, X. Zhang, J. Dong, D. Huang, Wuhan National Lab. for Optoelectonics (China)

678209 Investigation of ultrafast all-optical AND gate based on cascaded SOAs and optical filters [6782-08]

J. Xu, X. Zhang, J. Dong, D. Liu, D. Huang, Wuhan National Lab. for Optoelectonics (China)

$67820 \mathrm{~A}$ Analysis of femtosecond self-polarization modulation in semiconductor optical amplifier [6782-09]

M. Liu, A. Yang, Y. Sun, Beijing Institute of Technology (China) 
$6782 \mathrm{OB} \quad 1.55 \mu \mathrm{m}$ extremely efficient and polarization insensitive tunable Mach-Zehnder wavelength duplexer based on an InGaAsP/InP ridge waveguide structure (Best Student Paper Award) [6782-11]

L. Xu, X. J. M. Leijtens, M. J. H. Sander-Jochem, T. de Vries, Y. S. Oei, P. J. van Veldhoven,

R. Nötzel, M. K. Smit, Technische Univ. Eindhoven (Netherlands)

6782 OC Ultrafast multifunctional all-optical logic gates based on single semiconductor optical amplifier [6782-12]

J. Dong, X. Zhang, Wuhan National Lab. for Optoelectonics (China); S. Fu, Nanyang Technological Univ. (Singapore); Y. Wang, D. Huang, Wuhan National Lab. for Optoelectonics (China)

6782 OD Electrooptic properties of InGaAsP-based asymmetric double quantum well electroabsorption modulators [6782-13]

D. K. Kim, D. S. Citrin, Georgia Institute of Technology (USA) and Georgia Tech-CNRS, Georgia Tech Lorraine (France)

$6782 \mathrm{OE}$ The spectral feature analysis of semiconductor thin disk laser [6782-14]

C. He, Changchun Institute of Optics, Fine Mechanics and Physics (China) and Graduate School of the Chinese Academy of Science (China); L. Qin, Changchun Institute of Optics, Fine Mechanics and Physics (China); J. Li, L. Cheng, X. Liang, Changchun Institute of Optics, Fine Mechanics and Physics (China) and Graduate School of the Chinese Academy of Science (China); Y. Ning, L. Wang, Changchun Institute of Optics, Fine Mechanics and Physics (China)

6782 OF Variable wavelength conversion based on fan-out grating in QPM-LN [6782-15] Y. Wang, Y. Huang, Z. Weng, H. Yan, R. Ye, J. Zhu, Xiamen Univ. (China)

\section{PHOTONIC INTEGRATION}

$6782 \mathrm{OH}$ Design and fabrication of a novel monothically integrated dual-wavelength tunable photodetector [6782-17]

J. Lv, H. Huang, Y. Huang, X. Ren, A. Miao, Y. Li, H. Du, Q. Wang, Beijing Univ. of Posts and Telecommunications (China)

6782 Ol Multiplication characteristics of InP/InGaAs avalanche photodiodes with thick multiplication and charge layers [6782-18]

Y. Zhao, Wuhan National Lab. for Optoelectonics (China)

$67820 \mathrm{~J}$ On the performance analysis and design of a novel shared-layer integrated device using RCE-p-i-n-PD/SHBT [6782-19]

S. Zhou, Zhejiang Univ. of Technology (China); D. Xiong, Guangdong Univ. of Technology (China); Y. Qin, Zhejiang Univ. of Technology (China); H. Cui, Y. Chong, A. Miao, J. LV, Beijing Univ. of Posts and Telecommunications (China); J. Gao, Institute of Semiconductors (China)

6782 OK Modulation responses and problems of a novel monolithically integrated optical transceiver for EPON [6782-20]

H. Zhang, W. Li, T. Wang, Wuhan National Lab. for Optoelectonics (China) 
6782 OL InP-based optoelectronic components for all optical communication (Invited Paper) [6782-21]

Y. Baek, D. K. Oh, Electronics and Telecommunications Research Institute (South Korea)

MICRO LASERS

6782 OM InP-based long wavelength VCSELs: their characteristics and applications (Invited Paper) [6782-22]

N. Nishiyama, Tokyo Institute of Technology (Japan); C. Caneau, M. Sauer, A. Kobyakov, C. E. Zah, Corning Inc. (USA)

6782 ON Moving from ultrafast VECSELs to MIXSELs: a new class of ultrafast semiconductor lasers (Invited Paper) [6782-23]

T. Südmeyer, D. J. H. C. Maas, A.-R. Bellancourt, B. Rudin, M. Golling, H. J. Unold, U. Keller, ETH Zürich (Switzerland)

678200 High power VCSEL device with periodic gain active region [6782-24]

Y. Q. Ning, L. Qin, Y. F. Sun, T. Li, J. J. Cui, B. Peng, G. Y. Liu, Y. Zhang, Y. Liu, L. J. Wang, Changchun Institute of Optics, Fine Mechanics and Physics (China); D. F. Cui, Z. Y. Xu, Institute of Physics (China)

6782 OP Loss-reduced semiconductor ring lasers based on active vertical coupler structure and two-section rectangular cavity [6782-25]

R. Zhang, O. Ansell, Z. Ren, S. Yu, Univ. of Bristol (United Kingdom)

\section{NOVEL APPLICATION}

6782 OR Optical gain in $407 \mathrm{~nm}$ and $470 \mathrm{~nm}$ In GaN/GaN heterostructures: signature of quantum-dot states [6782-27]

B. Witzigmann, S. Steiger, M. Tomamichel, R. Veprek, ETH Zürich (Switzerland); U. T. Schwarz, Univ. of Regensburg (Germany)

6782 OS Analysis of the focusing performance of microlens made of anisotropically dielectric material by multi-wavelength illumination [6782-28]

J. Liu, S. Wang, F. Sun, C. Hu, G. Zhang, Beijing Jiaotong Univ. (China)

6782 OT Applications of swept light sources in imaging, sensor, and tests (Invited Paper) [6782-29]

T. Li, Y. Tang, W. Xu, Q. Qi, D. Eu, InPhenix, Inc. (USA)

\section{QUANTUM WELL OPTICAL MODULATORS}

$67820 \mathrm{U}$ Design and fabrication of high-performance InGaAsP/InP electroabsorption modulator [6782-37]

H. Yang, M. K. Chin, Nanyang Technological Univ. (Singapore); D. C. S. Lim, DSO National Labs. (Singapore); J. Zhou, Institute of Semiconductors (China); S. Lee, Nanyang Technological Univ. (Singapore); Y. Cheng, H. Zhu, W. Chen, Institute of Semiconductors (China) 
6782 OW Nano-structured special quantum well for high-performance optical modulators (Invited Paper) [6782-39]

T. Arakawa, Yokohama National Univ. (Japan); K. Tada, Kanazawa Institute of Technology (Japan)

6782 OY Design and performance of monolithic integrated electro-absorption modulated distributed feedback laser [6782-41]

Y. Cheng, J. Pan, F. Zhou, B. Wang, H. Zhu, L. Zhao, W. Wang, Institute of Semiconductors (China)

\section{PHOTONIC CRYSTALS AND FIBERS}

$67820 Z$ Silicon based ultra-compact modulator with photonic crystal [6782-30]

R. Hao, A. Mao, J. Feng, D. Gao, Wuhan National Lab. for Optoelectonics (China);

Z. Zhou, Wuhan National Lab. for Optoelectonics (China) and Georgia Institute of

Technology (USA); D. S. Citrin, Georgia Institute of Technology (USA)

678210 Negative refraction and birefringence in a two-dimensional flat perfect photonic crystal [6782-31]

Z. Li, Univ. of Shanghai for Science and Technology (China) and Henan Univ. (China);

B. Liang, H. Guo, J. Chen, S. Zhuang, Univ. of Shanghai for Science and Technology (China)

678211 Broad-band local field enhancement of a 2D nano-cavity [6782-32]

X. Su, F. Liu, J. Liu, S. Jian, Beijing Jiaotong Univ. (China)

678212 Wide-band transmission of slow light in one-dimensional photonic crystal coupled resonator optical waveguide [6782-33]

C. Li, H. Tian, B. Liu, Y. Ji, Beijing Univ. of Posts and Telecommunications (China)

678213 Continuous-wave optical fiber based supercontinuum light source [6782-34]

Z. G. Lu, National Research Council (Canada); Y. Song, National Research Council (Canada) and Concordia Univ. (Canada); J. R. Liu, National Research Council (Canada); X. P. Zhang, Concordia Univ. (Canada)

678214 Hybrid mode-locking based on nonlinear polarization rotation in a SOA fiber ring laser [6782-35]

F. Wang, Wuhan National Lab. for Optoelectonics (China) and Chongqing Institute of Technology (China); X.-L. Zhang, Chongqing Institute of Technology (China); Z.-M. Wu, G.-Q. Xia, Southwest Univ. (China)

678215 Liquid crystal photonic bandgap fiber components (Invited Paper) [6782-36]

L. Scolari, T. T. Alkeskjold, D. Noordegraaf, Technical Univ. of Denmark (Denmark); G. Tartarini, P. Bassi, Univ. of Bologna (Italy); A. Bjarklev, Technical Univ. of Denmark (Denmark) 
$678217 \quad \lambda / 4$ phase-shifted distributed feedback lasers with chirped grating: dynamic single-mode and modulation characteristics analyses [6782-43]

X.-H. Jia, Sichuan Normal Univ. (China); Z.-M. WU, G.-Q. Xia, Southwest Univ. (China);

D.-Z. Zhong, Wuyi Univ. (China); F. Wang, Chongqing Institute of Technology (China); J.-G. Wu, Southwest Univ. (China); H.-T. Chen, The Chinese People's Armed Police Force Academy (China)

678218 Field trial of $160 \mathrm{~Gb} / \mathrm{s}$ all-optical packet switching (Invited Paper) [6782-44]

Y. Liu, Eindhoven Univ. of Technology (Netherlands) and Univ. of Electronic Science and Technology of China (China); J. Herrera, Eindhoven Univ. of Technology (Netherlands) and Univ. Politécnica de Valencia (Spain); O. Raz, E. Tangdiongga, Eindhoven Univ. of Technology (Netherlands); J. Marti, F. Ramos, Univ. Politècnica de València (Spain); G. Maxwell, A. Poustie, Ctr. for Integrated Photonics Ltd. (United Kingdom); H. C. H. Mulvad, Technical Univ. of Denmark (Denmark); M. T. Hill, H. de Waardt, G. D. Khoe,

A. M. J. Koonen, H. J. S. Dorren, Eindhoven Univ. of Technology (Netherlands)

678219 Theoretical analysis of nonlinear polarization rotation influence on optical sampling in semiconductor optical amplifier [6782-45]

M. Liu, A. Yang, Y. Sun, Beijing Institute of Technology (China)

67821 A Design of all-optical UWB monocycle generation for UWB-over-fibre communications [6782-46]

J. Dong, X. Zhang, J. Xu, D. Huang, Wuhan National Lab. for Optoelectonics (China)

6782 1B A simple approach of high-purity millimeter-wave signal photonic generation [6782-47] T. Wang, M. Chen, H. Chen, S. Xie, Tsinghua Univ. (China)

TUNABLE LASERS

6782 1C Widely tunable lasers based on mode-hop-free semiconductor laser array (Invited Paper) [6782-48]

T. Kurobe, T. Kimoto, K. Muranushi, T. Mukaihara, M. Ariga, T. Kagimoto, N. Kagi, N. Matsuo, A. Kasukawa, The Furukawa Electric Co., Ltd. (Japan)

6782 1D Automated chip-on-carrier screening of a SOA integrated full band tunable laser (DSDBR) [6782-49]

C. Wang, Bookham Technology (Shenzhen) Co., Ltd. (China); G. Dimitropoulos, A. J. Ward, Bookham Technology plc (United Kingdom); G. Yang, X. Wu, Bookham Technology (Shenzhen) Co., Ltd. (China)

$67821 \mathrm{E} \quad$ A compact tunable transmitter assembly for high performance $10 \mathrm{Gbps}$ optical systems [6782-50]

Y. Zhang, F. Liu, S. Yu, N. Zhang, Bookham Technology Co. Ltd. (China); P. Mitchell,

S. Mayne, L. Nelson, Bookham Technology (United Kingdom) 
$6782 \mathrm{IF}$ Static properties of widely tunable external cavity semiconductor laser with sampled fiber grating [6782-51]

X. He, Wuhan National Lab. for Optoelectonics (China) and Hong Kong Polytechnic Univ. (Hong Kong China); Y. Yu, D. Huang, Wuhan National Lab. for Optoelectonics (China);

D. N. Wang, Hong Kong Polytechnic Univ. (Hong Kong China)

$67821 \mathrm{G}$ Theoretical model and simulation of the extremely short external cavity semiconductor laser [6782-52]

G. Xia, Z. WU, J. WU, Z. Li, Q. Yang, B. Yang, Southwest Univ. (China)

$67821 \mathrm{H} \quad$ Trend and applications of tunable semiconductor lasers (Invited Paper) [6782-53]

S.-L. Lee, Y.-T. Pan, Y.-J. Hung, C.-L. Yao, C.-H. Cheng, S.-T. Ji, National Taiwan Univ. of

Science and Technology (Taiwan)

\section{COST-EFFECTIVE COMPONENTS}

$678211 \quad$ Advanced component technologies for colourless access networks (Invited Paper) [6782-54]

C. Kazmierski, Alcatel-Thales III-V Lab. (France); P. Chanclou, France Telecom Division R\&D (France); J. A. Lazaro, Univ. Politècnica de Catalunya (Spain)

$67821 \mathrm{~J} \quad$ Cost-effective telecom/datacom semiconductor lasers (Invited Paper) [6782-55] N. Chen, D. T. R. Chen, W. Hsin, S. B. Chen, F. Xiong, H. Erlig, P. Chen, X. Yeh, D. C. Scott, Archcom Technology, Inc. (USA); A. Sherer, California Institute of Technology (USA)

$67821 \mathrm{~K} \quad 980 \mathrm{~nm}$ pump laser module with $750 \mathrm{~mW}$ output power [6782-56]

B. Guo, J. Lin, Q. He, Bookham Technology Co., Ltd. (China); S. Loten, J. Greatrex, Bookham Technology plc (United Kingdom); H.-U. Pfeiffer, S. Mohrdiek, T. Pliska, Bookham AG (Switzerland)

$67821 \mathrm{~L}$ Design of taper coupler for effective laser and single mode fiber coupling with large tolerance [6782-57]

J. Zhang, R. V. Pamidighantam, J. H.-S. Lau, Q. Zhang, C. Jayakrishnan, C. W. Tan, M. C. Jong, C. Teo, L. Wei, D. L. Kwong, Institute of Microelectronics (Singapore)

$67821 \mathrm{M}$ Photonics studies on dilute nitrides at long wavelength for telecommunication (Invited Paper) [6782-58]

C. S. Peng, M. Pessa, Tampere Univ. of Technology (Finland)

\section{MODULATORS AND SWITCHES}

6782 IN Intersubband photonic devices by group-III nitrides (Invited Paper) [6782-59]

P. Holmström, Royal Institute of Technology (Sweden) and Sophia Univ. (Japan); X. Y. Liu, Chalmers Univ. of Technology (Sweden); H. Uchida, Sophia Univ. (Japan); T. Aggerstam, Royal Institute of Technology (Sweden); A. Kikuchi, K. Kishino, Sophia Univ. (Japan);

S. Lourdudoss, Royal Institute of Technology (Sweden); T. G. Andersson, Chalmers Univ. of Technology (Sweden); L. Thylén, Royal Institute of Technology (Sweden) 
6782 IP Investigation on electro-optic single-sideband modulation using period phase reversal electrode [6782-61]

J. Hu, X. Yuan, Wuhan National Lab. for Optoelectonics (China)

$67821 Q$ Design of a novel high-speed magneto-optic modulator [6782-62]

J. Wan, Y. Huang, Z. Weng, H. Yan, Y. Wang, Z. Wu, R. Ye, Xiamen Univ. (China)

\section{Part Two}

NOVEL PHOTONICS COMPONENTS

6782 IR Birefringent hollow core fibers (Invited Paper) [6782-63]

P. J. Roberts, Danish Technical Univ. (Denmark)

6782 is Experimental demonstration of PPLN-based double ring fiber laser and its application to $\mathbf{4 0}$ Gb/s wavelength conversion [6782-64]

J. Wang, J. Sun, Q. Sun, Wuhan National Lab. for Optoelectonics (China)

$67821 \mathrm{~T} \quad$ Light waveguide electro-optical printed circuit board [6782-65]

F. Luo, M. Cao, X. Zhou, J. XU, Z. Luo, J. Yuan, Huazhong Univ. of Science and Technology (China) and Wuhan National Lab. for Optoelectronics (China); L. Zong, C. Zhang,

Huazhong Univ. of Science and Technology (China)

$67821 \mathrm{U}$ Carbon-nanotube-based photonic devices (Invited Paper) [6782-68]

S. Yamashita, Univ. of Tokyo (Japan)

\section{QUANTUM STRUCTURE DEVICES}

$67821 \mathrm{~V}$ InAs/InP-based quantum dot mode-locked semiconductor lasers at $1.5 \mu \mathrm{m}$ (Invited Paper) [6782-69]

G.-H. Duan, F. Lelarge, B. Dagens, R. Brenot, A. Accard, A. Shen, F. van Dijk, D. Make,

O. Le Govezigou, L. Le Govezigou, J.-G. Provost, F. Poingt, J. Landreau, O. Drisse,

E. Derouin, B. Rousseau, F. Pommereau, Alcatel Thales III-V Lab. (France)

6782 IW Influence of flux on the growth of InAs quantum dots on GaAs patterned substrate [6782-70] Y. Song, Z. YU, Y. Liu, Beijing Univ. of Posts and Telecommunications (China) and Key Lab. of Optical Communication and Lightwave Technologies (China)

$67821 \mathrm{X}$ The strain energy distribution of the capping layer surface for InAs/GaAs quantum dot along different growth directions [6782-71]

Z. YU, Y. Liu, Beijing Univ. of Posts and Telecommunications (China)

6782 IY Quantum-dot semiconductor waveguide devices [6782-72]

Z. G. Lu, J. R. Liu, S. Raymond, P. J. Poole, P. J. Barrios, S. Haffouz, D. Poitras, G. Pakulski, National Research Council (Canada); S. Taebi, National Research Council (Canada) and Univ. of Ottawa (Canada); Y. Song, National Research Council (Canada) and Concordia Univ. (Canada); X. P. Zhang, Concordia Univ. (Canada); T. Hall, Univ. of Ottawa (Canada) 
678212 The couple electronic state of the stack quantum dots by axial symmetrical finite element analysis [6782-73]

Y. Liu, Z. Yu, Beijing Univ. of Posts and Telecommunications (China) and Key Lab. of Optical Communication and Lightwave Technologies (China); X. Ren, Key Lab. of Optical Communication and Lightwave Technologies (China)

678220 Determination on wave function of quantum structures using finite-difference time domain [6782-74]

B. Jia, Z. YU, Y. Liu, Beijing Univ. of Posts and Telecommunications (China) and Key Lab. of Optical Communication and Lightwave Technologies (China)

POSTER SESSION

678222 Resonant-cavity based monolithic white light-emitting diode [6782-76]

L. Huang, D. Huang, F. Wen, Wuhan National Lab. for Optoelectonics (China)

678223 Multi-quantum-well InGaNAs/GaAs resonant cavity enhanced photodetector with integrated vertical taper structure [6782-77]

Y. XU, Y.-Q. Huang, H. Huang, X.-M. Ren, Beijing Univ. of Posts and Telecommunications (China)

678224 High power vertical cavity surface-emitting laser with high reliability [6782-78]

C. Yan, Changchun Univ. of Science and Technology (China); G. LU, C. He, L. Qin,

Changchun Institute of Optics, Fine Mechanics and Physics (China)

678225 Characterization of white OLEDs [6782-79]

W. Chen, L. LU, Univ. of Electronic Science and Technology of China (China)

678226 Parameter optimization of nonlinear SOA in an SOA-MZI packet-level self-synchronization scheme [6782-80]

L. Cai, M. Zhang, H. Han, W. Yang, P. Ye, Beijing Univ. of Posts and Telecommunications (China)

678227 Fine-tuning of the spectral efficiency based on tunneling splitting in multiple quantum well system [6782-81]

C. Huang, Hunan Institute of Science and Technology (China); J. Sun, Wuhan National Lab. for Optoelectronics (China); J. Liu, Hunan Institute of Science and Technology (China) and Wuhan National Lab. for Optoelectronics (China); W. Hu, Hunan Institute of Science and Technology (China)

678228 Large aperture low threshold current 980nm VCSELs fabricated with pulsed anodic oxidation [6782-82]

J. Cui, Changchun Institute of Optics, Fine Mechanics and Physics (China) and Graduate School of Chinese Academy of Sciences (China); Y. Ning, Changchun Institute of Optics, Fine Mechanics and Physics (China); T. Li, G. Liu, Y. Zhang, B. Peng, Y. Sun, Changchun Institute of Optics, Fine Mechanics and Physics (China) and Graduate School of Chinese Academy of Sciences (China); L. Wang, Changchun Institute of Optics, Fine Mechanics and Physics (China) 
678229 Buffer optimization for high-quality InP-on-GaAs(001) quasi-substrates [6782-83] J. Zhou, X. Ren, D. Xiong, J. LV, Q. Wang, Y. Huang, H. Huang, S. Cai, Beijing Univ. of Posts and Telecommunications (China)

6782 2A Novel scheme to increase the operation speed of a SOA for all-optical wavelength conversion [6782-84]

Z. Wu, Y. Huang, Z. Weng, H. Yan, Y. Wang, J. Wan, R. Ye, Xiamen Univ. (China)

6782 2C Novel optical modulator of silicon photonic crystals [6782-86]

J. Li, J. Li, China Jiliang Univ. (China)

6782 2D Structural and optical properties of InGaN/GaN multiple quantum wells structure for ultraviolet emission [6782-87]

B. Wang, Hebei Univ. of Science and Technology (China) and Institute of Semiconductors (China); X. Wang, Institute of Semiconductors (China); H. Wen, R. Wu, Hebei Univ. of Science and Technology (China); G. Hu, J. Ran, H. Xiao, Institute of Semiconductors (China)

$67822 \mathrm{E}$ Theory study of AllnGaN quantum well with different barriers [6782-88]

F. Wen, Huazhong Univ. of Science and Technology (China) and Univ. of Electronic Science and Technology (China); D. Liu, Huazhong Univ. of Science and Technology (China); L. Huang, Wuhan National Lab. for Optoelectronics (China)

$67822 \mathrm{~F}$ Picosecond pulse Raman amplification and controlled time delay in silicon-on-insulator waveguides [6782-89]

J. Wu, F. Luo, M. Cao, Q. Zhang, Y. Huang, Wuhan National Lab. for Optoelectronics (China)

$67822 \mathrm{G}$ Research of photodetector and its array in standard CMOS technology [6782-90] J. Bian, Jiangsu Polytechnic Univ. (China) and Xiamen Univ. (China); X. Cheng, C. Chen, Xiamen Univ. (China)

$67822 \mathrm{H} \quad$ Single-SOA-based all-optical XNOR and AND gates [6782-91]

P. Li, Wuhan National Lab. for Optoelectronics (China) and Huazhong Univ. of Science and Technology (China); D. Huang, X. Zhang, Wuhan National Lab. for Optoelectronics (China); G. Zhu, Wuhan National Lab. for Optoelectronics (China) and Huazhong Univ. of Science and Technology (China)

$678221 \quad$ Luminescence properties of $\mathrm{Cu}$ and $\mathrm{Cu}, \mathrm{Al}$ doped $\mathrm{ZnS}$ quantum dots [6782-92]

X. Zhang, Tianjin Univ. of Technology (China) and Nankai Univ. (China); L. Li, Tianjin Univ. of Technology (China); X. Dong, G. Kai, Nankai Univ. (China); D. Dong, Y. Zhang, J. Li, Tianjin Univ. of Technology (China)

6782 2J NIR luminescence properties of $\mathrm{ZnS}: \mathrm{Er}, \mathrm{Yb}$ quantum dots [6782-93]

$X$. Zhang, Nankai Univ. (China) and Tianjin Univ. of Technology (China); X. Dong, Nankai Univ. (China); L. Li, Tianjin Univ. of Technology (China); Z. Wang, Y. Liu, Nankai Univ. (China);

D. Dong, Y. Zhang, Tianjin Univ. of Technology (China); G. Kai, Nankai Univ. (China)

$67822 \mathrm{~K}$ Two-dimensional photonic crystal polarizer modulated by silicon resin [6782-94]

C. Tan, X. Huang, South China Normal Univ. (China) 
$6782 \mathrm{2L}$ Simulation and analysis of gain-transparent SOA used as optical phase-modulator in DPSK applications [6782-95]

W. Hong, Wuhan National Lab. for Optoelectronics (China) and Huazhong Univ. of Science and Technology (China); D. Huang, X. Zhang, Wuhan National Lab. for Optoelectronics (China); G. Zhu, Wuhan National Lab. for Optoelectronics (China) and Huazhong Univ. of Science and Technology (China);

$67822 \mathrm{M}$ Finite element method analysis of $\mathrm{LiNbO}_{3}$ fiber type modulator [6782-96]

J. Li, J. Li, China Jiliang Univ. (China)

6782 2N Noise-reduction of experimental optical chaos and its attributes [6782-99]

Z. Zhu, Y. Meng, N. Fang, Z. Huang, Shanghai Univ. (China)

6782 2P Modeling of dynamics of DBR tunable lasers based on transfer matrix method [6782-101]

S. Kai, Y. Yu, Wuhan National Lab. for Optoelectronics (China)

$67822 Q \quad$ The spectrum of chaos signal based on Wigner distribution [6782-102]

X. Guo, N. Fang, Z. Huang, Shanghai Univ. (China)

6782 2R Activation experiments and quantum efficiency theory on gradient-doping NEA GaAs photocathodes [6782-103]

J. Zou, Nanjing Univ. of Science and Technology (China) and East China Institute of Technology (China); Z. Yang, J. Qiao, P. Gao, B. Chang, Nanjing Univ. of Science and Technology (China)

678225 Design of high performance DBR lasers for WDM fiber optic communications [6782-104] H. H. Yee, C. L. Xiao, C. K. Liao, H. Y. Tung, H. H. Lu, National Taipei Univ. of Technology (Taiwan)

6782 W Simulation of integrated DFB lasers in serial in a convenient model with transfer matrices method [6782-108]

H. Xie, Y. Wang, W. Zhang, L. He, Y. Sha, W. Zhang, Beijing Univ. of Technology (China)

$67822 X$ Design of preamplifier for PIN/ HBT OEIC optical receiver [6782-109]

Q. Wu, Y.-Q. Huang, H. Huang, H. L. Cui, Y. Q. Li, A. Miao, X.-M. Ren, Beijing Univ. of Posts and Telecommunications (China)

$67822 \mathrm{Y}$ Tunable ultraviolet laser source from a frequency doubled Alexandrite laser [6782-110] S. Liu, Changchun Institute of Optics, Fine Mechanics and Physics (China) and Graduate School of Chinese Academy of Sciences (China); J. Liu, China Northern Institute of Electric Equipment (China); L. Wang, Changchun Institute of Optics, Fine Mechanics and Physics (China)

$67822 Z$ The role of dispersive magnetic permeability in ultrashort electromagnetic pulse propagation in nonlinear metamaterials [6782-111]

S. Wen, Q. Lv, X. Cheng, L. Jiang, W. Su, Hunan Univ. (China)

678230 All-optical ultrawideband monocycle and doublet generation using cascaded PPLN waveguides [6782-112]

J. Wang, J. Sun, Q. Sun, Wuhan National Lab. for Optoelectronics (China) 
678231 Analysis and measurement of thermal-electrical performance of microbolometer detector [6782-113]

L. Sun, B. Chang, J. Zhang, Y. Qiu, Y. Qian, S. Tian, Nanjing Univ. of Science and Technology (China)

678232 Three-input ultrahigh-speed all-optical AND and NOR gates based on orthogonal dualpump four-wave mixing in semiconductor optical amplifier with PoISK modulated signals [6782-114]

P. Li, Wuhan National Lab. for Optoelectronics (China) and Huazhong Univ. of Science and Technology (China); D. Huang, X. Zhang, Wuhan National Lab. for Optoelectronics (China); G. Zhu, Wuhan National Lab. for Optoelectronics (China) and Huazhong Univ. of Science and Technology (China)

678233 Theoretical investigation and experimental demonstration of nonlinear patterning suppression in bulk semiconductor optical amplifiers for transient cross phase modulation [6782-115]

E. Zhou, X. Zhang, D. Huang, Wuhan National Lab. for Optoelectronics (China)

678234 Structural and photoluminescence properties of porous silicon with r.f.-sputtered thin films [6782-116]

Y. Zhang, Xi'an Jiatong Univ. (China); Z. Jia, Xinjiang Univ. (China)

678235 The cavity enhancing effect of F-P cavity mode on the non-degenerated four-wave mixing in distributed-feedback semiconductor laser diodes [6782-117]

J. Wu, G. Xia, Southwest Univ. (China); X. Jia, Sichuan Normal Univ. (China); X. Yan, J. Li, $X$. Wang, Z. Wu, Southwest Univ. (China)

678237 Performance analysis of all optical XOR gate using quantum dot semiconductor optical amplifier-based Mach-Zehnder interferometer [6782-119]

H. Han, F. Zhang, W. Yang, L. Cai, M. Zhang, P. Ye, Beijing Univ. of Posts and Telecommunications (China)

678238 High efficiency $160 \mathrm{~Gb} / \mathrm{s}$ all-optical wavelength converter based on terahertz optical asymmetric demultiplexer with quantum dot semiconductor optical amplifier [6782-120] H. Han, F. Zhang, W. Yang, L. Cai, M. Zhang, P. Ye, Beijing Univ. of Posts and Telecommunications (China)

678239 Linear frequency modulation with electronic-optics modulator [6782-121]

C. Cao, X. Zeng, Y. Zheng, H. Liu, X. Zhao, Xidian Univ. (China)

6782 3A Study on the collimation of laser diode beams [6782-122]

Y. Zheng, X. Zeng, C. Cao, Z. Feng, Xidian Univ. (China)

$67823 \mathrm{~B}$ Focused light from a metallic nanostructure composed by a nanoparticle and a nanoslit [6782-123]

G. Zhang, J. Liu, C. Hu, F. Sun, X. SU, Beijing Jiaotong Univ. (China) 
$67823 \mathrm{C}$ Numerical investigation of differential phase noise and its power penalty for optical amplification using semiconductor optical amplifiers in DPSK applications [6782-124]

W. Hong, Wuhan National Lab. for Optoelectronics (China) and Huazhong Univ. Of Science and Technology (China); D. Huang, X. Zhang, Wuhan National Lab. for Optoelectronics (China); G. Zhu, Wuhan National Lab. for Optoelectronics (China) and Huazhong Univ. of Science and Technology (China)

6782 3D On-line measurement system of GaAs photocathodes and its applications [6782-125] J. Zou, Nanjing Univ. of Science and Technology (China) and East China Institute of Technology (China); L. Feng, G. Lin, Y. Rao, East China Institute of Technology (China); Z. Yang, Y. Qian, B. Chang, Nanjing Univ. of Science and Technology (China)

Author Index 


\title{
Conference Committee
}

\author{
Symposium Chairs
}

Chung-En Zah, Corning Inc. (USA)

Chaohui Ye, Wuhan National Laboratory for Optoelectronics (China)

Bingkun Zhou, Tsinghua University (China)

Yun C. Chung, Korea Advanced Institute of Science and Technology (South Korea)

Conference Chair

Yoshiaki Nakano, The University of Tokyo (Japan)

Conference Cochairs

Jens Buus, Gayton Photonics Ltd. (United Kingdom)

David S. Citrin, Georgia Institute of Technology (USA)

Jinzhong Yu, Institute of Semiconductors (China)

Program Committee

Alfred R. Adams, University of Surrey (United Kingdom)

Markus-Christian Amann, Walter Schottky Institute (Germany)

Dan Botez, University of Wisconsin, Madison (USA)

Kent D. Choquette, University of Illinois at Urbana-Champaign (USA)

Jen-Inn Chyi, National Central University (Taiwan)

Akihiko Kasukawa, The Furukawa Electric Company, Ltd. (Japan)

Fumio Koyama, Tokyo Institute of Technology (Japan)

Yong-Hee Lee, Korea Advanced Institute of Science and Technology

(South Korea)

Yu-Hwa Lo, University of California, San Diego (USA)

Kikuo Makita, NEC Corporation (Japan)

Berthold E. Schmidt, Bookham AG (Switzerland)

Meint K. Smit, Technische Universiteit Eindhoven (Netherlands)

JunQiang Sun, Huazhong University of Science and Technology

(China)

Shinji Tsuji, Hitachi Central Research Laboratory (Japan)

Chih-Chung Yang, National Taiwan University (Taiwan)

Session Chairs

Silicon Photonics Symposium

Yoshiaki Nakano, The University of Tokyo (Japan) 
All-Optical Processing

Yong Liu, University of Electronic Science and Technology of China (China)

Best Student Paper Session

Yoshiaki Nakano, The University of Tokyo (Japan)

Photonic Integration

Nong Chen, Archcom Technology Inc. USA (USA)

Micro Lasers

Shinji Tsuji, Hitachi, Ltd. (Japan)

Novel Application

Shinji Tsuji, Hitachi, Ltd. (Japan)

Quantum Well Optical Modulators

Jianyi Yang, Zhejiang University (China)

Photonic Crystals and Fibers

Shinji Yamashita, The University of Tokyo (Japan)

Telecom and RF Photonics

Christophe Kazmierski, Consultant (France)

Tunable Lasers

Jens Buus, Gayton Photonics Ltd. (United Kingdom)

Cost-Effective Components

Guang-Hua Duan, Alcatel-Thales III-V Laboratory (France)

Modulators and Switches

Jinzhong Yu, Institute of Semiconductors (China)

Novel Photonics Components

JunQiang Sun, Huazhong University of Science and Technology (China)

Quantum Structure Devices

Norbert Grote, Fraunhofer-Gesellschaft (Germany) 